\title{
An assessment of the association between antenatal care and child malnutrition in Bangladesh
}

\author{
AFRINA SULTANA TOMA ${ }^{\mathrm{A}, \mathrm{C}, \mathrm{D}}$, ASHIS TALUKDER ${ }^{A-D}$, SHABNUM SHIRIN KHAN ${ }^{\mathrm{D}-\mathrm{F}}$, \\ SHAHARIOR RAHMAN RAZUD-F \\ ORCID ID: 0000-0002-5031-1128
}

Khulna University, Bangladesh

A - Study Design, B - Data Collection, C - Statistical Analysis, D - Data Interpretation, E - Manuscript Preparation, F - Literature Search, G - Funds Collection

Summary Background. Child malnutrition in third-world countries is linked with a number of factors, including antenatal care services. Objectives. This study attempts to examine the association between antenatal care services and child malnutrition in Bangladesh through analyzing the data set extracted from the nationally renowned Bangladesh Demographic and Health Survey (BDHS) 2014. Material and methods. The information was collected from ever married women who were 15 to 49 years of age. The total number of observations was 6,965 , and the response variable of our study, child's nutritional status (severely malnourished, moderately malnourished, nourished), was created by calculating the $Z$ score for the anthropometric index weight-for-age. We conducted a chi-square test of independence to identify the association between selected covariates and the nutritional status of children and applied the cumulative logit model to assess the marginal effect of antenatal care services on child malnutrition.

Results. The results show that children whose mothers received antenatal care (ANC) from skilled ANC providers had a reduced risk of falling into the malnourished category of nutritional status when we considered only two variables (ANC visit and ANC provider) as covariates. Although the variable ANC visit was found significant $(\mathrm{OR}=0.815,95 \% \mathrm{Cl}=0.665,0.972)$ after controlling demographic and clinical covariates, the variable ANC provider appeared insignificant $(O R=1.025,95 \% \mathrm{Cl}=0.880,1.225)$ in affecting child malnutrition. Conclusions. The study concludes that an antenatal care visit has a significant association with child malnutrition. Thus, antenatal care visits could be beneficial in minimizing child malnutrition in Bangladesh.

Key words: child, malnutrition, Bangladesh.

Toma AS, Talukder A, Khan SS, Razu SR. An assessment of the association between antenatal care and child malnutrition in Bangladesh. Fam Med Prim Care Rev 2018; 20(4): 373-378, doi: https://doi.org/10.5114/fmpcr.2018.79350.

\section{Background}

Child malnutrition is one of the major health concerns in Bangladesh. Inadequate nutrition and childhood infection are the major causes behind this. Child malnutrition can be defined as a pathological state resulting from inadequate nutrition, including under-nutrition (protein-energy malnutrition), over-nutrition (overweight and obesity) and deficiency diseases due to insufficient intake of one or more specific nutrients [1]. According to UNICEF, household, food, security and healthy environment are essential factors for good child nutrition intake and a healthy life. Child malnutrition estimates for the indicators stunting (height-for-age), wasting (weight-for-height) and underweight (weight-for-age) describe the magnitude and pattern of under and over nutrition [2].

Studies suggest that child malnutrition is still one of the major health concerns around the world [3-5]. There are many regions in developing countries that are still below the poverty line, or more specifically, the people living in those areas are the poorest within the country. The children belonging to the poorest families are more prone to mortality and morbidity due to child malnutrition, as they have less access to the basic needs of life [6-8]. Since an antenatal care visit is medical surveillance and reviews performed during pregnancy for the early detection of possible complications of pregnancy, ANC service can reduce child deaths in neonatal periods - the first four weeks of the infants' life to a noticeable extent [9]. Though the World Health Organization (WHO) recommends a set of four antenatal care visits during the entire pregnancy cycle, according to UNICEF, only half of the total women worldwide get a regular ANC visit.

There is empirical evidence of significant relations between a mother's BMI and the malnutrition of their children $[10,11]$. Women with low BMI are more likely to give birth to malnourished children, and women with higher BMI (obese) are prone to postpartum hemorrhaging and preterm delivery [12]. It is evident that children aged six months or less face the lowest prevalence of malnutrition (about 10\%), and children aged 12 to 23 months face the highest prevalence of malnutrition (about 59\%) [13]. Another study suggests that children who are small in size at birth are two times more at risk of being malnourished than the children who are of a larger size [14]. Alongside this, the odds for malnutrition were higher in cases of illiterate parents compared to literate parents [11], while women with $\mathrm{CMD}$ (common mental disorders) are more likely to give birth to malnourished children [15].

Malnutrition is a common phenomenon in third-world countries, as it exists both in urban and rural areas, but the prevalence of malnutrition is far higher in rural areas than urban areas [16]. A study suggests that the wealthiest people use antenatal care and professional delivery care $80 \%$ of the time or more, irrespective of the average level of the country [17]. It is evident that the most important factors that affect a mother's health and the child's nutritional status are the mother's and father's education and the family's financial status $[18,19]$. Though the rate of chronic malnutrition in Bangladesh has declined significantly over the last decade [20], this rate can be decreased even more rapidly if people are made aware of ANC 
programs. Under such circumstance, studies on the link between child malnutrition and antenatal care become important to avoid health risks for both mothers and their children.

\section{Objectives}

This study attempts to examine the association between antenatal care services and child malnutrition in Bangladesh through analyzing the data set extracted from the nationally renowned Bangladesh Demographic and Health Survey (BDHS) 2014.

\section{Material and methods}

\section{Data and variables}

For this study, a database consisting of the variables used in our analyses were extracted from the nationally representative sample survey, Bangladesh Demographic and Health Survey (BDHS) 2014. The BDHS 2014 dataset was collected through a joint effort of the National Institute of Population Research and Training (Bangladesh), ICF International (USA) and Mitra and Associates (Bangladesh). Since this survey uses samples from a finite population, an estimation and test based on this data requires adjustment using appropriate sampling weights. In this paper, appropriate sampling weights were used in the analyses so that statistically valid inferences could be made.

In literature, there are three anthropometric indices of physical growth that are used to describe the nutritional status of children: height-for-age (stunting), weight-for-height (wasting) and weight-for-age (underweight). Among these indices, weight-for-age is used as a composite index of height-for-age and weight-for-height [20]. Therefore, in our study, we considered only weight-for-age for measuring the nutrition status of children under five years of age in Bangladesh.

To investigate the nutritional status of children, we first calculated the weight-for-age Z scores (WAZ) by using the formula:

$W A Z=\frac{\text { (individual's weight) }- \text { (median value of reference population) }}{\text { standard deviation value of reference population }}$

On the basis of WAZ, the nutritional status of children was divided into three ordinal categories to create the main response variable of this study:

Nutrition status $\left\{\begin{array}{c}\text { 1. severely malnourished }(<-3.0 \text { WAZ) } \\ \text { 2. moderately malnourished (-3.0 to }-2.0 \text { WAZ) } \\ \text { 3. nourished }(\geq 2.01 \text { WAZ) }\end{array}\right.$

Note that, for simplicity, the WHO AnthroPlus Software (version 3.2.2, 2011) [21] was used to calculate WAZ. After necessary modification and discarding all missing observations, the anthropometric data was available for 6,965 (weighed) children, and the created ordinal variable (nutrition status) was considered to be the main response variable.
Besides the main response variable, a set of covariates was considered, which are: antenatal care visit (yes, no), antenatal care provider (skilled, unskilled), child's age (0-11 months, 12-23 months, above 24 months), mother's education (no education, primary, secondary or higher), father's education (no education, primary, secondary or higher), wealth index (categorized on the basis of terciles), residence (urban, rural), number of children in the family $(1-2$, above 2$)$ and mother's BMI [thin (BMI <18.5), normal (BMI 18.5 to 24.9), over-weight (BMI > 24.9)].

\section{Cumulative logit model}

For subject $i$, let $Y_{i}(i=1,2, \ldots, n)$ be the ordinal response variable with categories $1, \ldots, j, \ldots, c$, and $x_{i}=\left(x_{i 1}, x_{i 2}, x_{i p}\right)^{\prime}$ 'be a column vector of the values of $p$ explanatory variables. Then the mathematical form of cumulative logit model can be written as:

$$
\operatorname{logit}\left[P\left(Y_{i} \leq \mathrm{j}\right)\right]=\alpha_{j}+b^{\prime} x_{i} \text { for } j=1,2, \ldots, \mathrm{c}-1 .
$$

In the above equation, $\operatorname{logit}\left[P\left(Y_{i} \leq \mathrm{j}\right)\right]=\log \left[P\left(Y_{i} \leq \mathrm{j}\right)\right) /\left(1-P\left(Y_{i} \leq \mathrm{j}\right)\right]$.

\section{Statistical analysis}

The relationship between selected explanatory variables and the child's nutritional status was assessed in both a bivariate and multivariate framework. In the bivariate setup, we conducted the chi-square test of independence. Mathematically, the chi-square statistic can be defined as:

$\chi^{2}=\sum_{i=1}^{n} \frac{\left(O_{i}-E_{i}\right)^{2}}{E_{i}}$

where $O_{i}$ and $E_{i}$ are the observed and expected frequency, respectively. The statistic follows a chi-square distribution with $(m-1)(n-1)$ degrees of freedom $(d f)$, where $m$ and $n$ are the number of categories of the covariates and response variable, respectively.

Since the main objective of this study is to explore the association between child malnutrition and ANC service, we considered two cumulative logit regression models in the multivariate framework. These are: Model I: considering only two covariates related to ANC services (antenatal care visit and antenatal care provider); Model II: covariate of Model I along with demographic and clinical variables (child's age, mother's education, father's education, wealth index, residence, mother's BMI) to examine the effect of ANC service after controlling the demographic, as well as clinical variables.

All procedures performed in this study involving human participants were in accordance with the ethical standards of the national research committee and with the 1964 Helsinki Declaration and its later amendments or comparable ethical standards.

\section{Results}

\section{Bivariate analysis}

The cross-classification of the selected explanatory variables by nutrition status are shown in Table 1 . From the table,

\begin{tabular}{|c|c|c|c|c|c|}
\hline \multirow[t]{2}{*}{ Covariates } & \multicolumn{3}{|l|}{ Nutrition status } & \multirow[t]{2}{*}{ Chi-square } & \multirow[t]{2}{*}{$p$} \\
\hline & $\begin{array}{l}\text { Severely malnourished } \\
n(\%)\end{array}$ & $\begin{array}{l}\text { Moderately malnourished } \\
n(\%)\end{array}$ & $\begin{array}{l}\text { Nourished } \\
n(\%)\end{array}$ & & \\
\hline \multicolumn{6}{|l|}{ ANC visit } \\
\hline $\begin{array}{l}\text { Yes } \\
\text { No }\end{array}$ & $\begin{array}{l}198(6.2) \\
110(13.0)\end{array}$ & $\begin{array}{l}626(19.6) \\
233(27.5)\end{array}$ & $\begin{array}{l}2,372(74.2) \\
505(59.6)\end{array}$ & 80.307 & $<0.001$ \\
\hline \multicolumn{6}{|c|}{ ANC provider } \\
\hline $\begin{array}{l}\text { Skilled } \\
\text { Unskilled }\end{array}$ & $\begin{array}{l}84(4.4) \\
114(8.8)\end{array}$ & $\begin{array}{l}339(17.9) \\
287(22.1)\end{array}$ & $\begin{array}{l}1,473(77.7) \\
899(69.2)\end{array}$ & 37.943 & $<0.001$ \\
\hline
\end{tabular}




\begin{tabular}{|c|c|c|c|c|c|}
\hline \multirow[t]{2}{*}{ Covariates } & \multicolumn{3}{|l|}{ Nutrition status } & \multirow[t]{2}{*}{ Chi-square } & \multirow[t]{2}{*}{$p$} \\
\hline & $\begin{array}{l}\text { Severely malnourished } \\
n(\%)\end{array}$ & $\begin{array}{l}\text { Moderately malnourished } \\
n(\%)\end{array}$ & $\begin{array}{l}\text { Nourished } \\
n(\%)\end{array}$ & & \\
\hline \multicolumn{6}{|l|}{ Child's age (months) } \\
\hline $\begin{array}{l}0-11 \\
12-23 \\
\text { Above } 24\end{array}$ & $\begin{array}{l}59(4.4) \\
126(8.7) \\
381(9.1)\end{array}$ & $\begin{array}{l}199(14.8) \\
326(22.4) \\
1164(27.9)\end{array}$ & $\begin{array}{l}1,086(80.8) \\
1,004(69.0) \\
2,620(62.9)\end{array}$ & 152.534 & $<0.001$ \\
\hline \multicolumn{6}{|l|}{ Father's education } \\
\hline $\begin{array}{l}\text { Primary or below } \\
\text { Secondary or higher }\end{array}$ & $\begin{array}{l}340(11.3) \\
226(5.7) \\
\end{array}$ & $\begin{array}{l}886(29.4) \\
803(20.3) \\
\end{array}$ & $\begin{array}{l}1,784(59.3) \\
2,926(74.0)\end{array}$ & 179.01 & $<0.001$ \\
\hline \multicolumn{6}{|l|}{ Mother's education } \\
\hline $\begin{array}{l}\text { Primary or below } \\
\text { Secondary or higher }\end{array}$ & $\begin{array}{l}424(11.1) \\
142(4.5) \\
\end{array}$ & $\begin{array}{l}1,088(28.4) \\
601(19.2)\end{array}$ & $\begin{array}{l}2,324(60.6) \\
2,384(76.2)\end{array}$ & 211.68 & $<0.001$ \\
\hline \multicolumn{6}{|l|}{ Wealth index } \\
\hline $\begin{array}{l}\text { Poor } \\
\text { Middle } \\
\text { Wealthy }\end{array}$ & $\begin{array}{l}300(13.1) \\
177(7.5) \\
89(3.8) \\
\end{array}$ & $\begin{array}{l}688(30.1) \\
603(25.5) \\
398(17.2) \\
\end{array}$ & $\begin{array}{l}1,298(56.8) \\
1,584(67.0) \\
1,828(79.0) \\
\end{array}$ & 0.322 & $<0.001$ \\
\hline \multicolumn{6}{|l|}{ Place of residence } \\
\hline $\begin{array}{l}\text { Urban } \\
\text { Rural }\end{array}$ & $\begin{array}{l}145(6.6) \\
421(8.8) \\
\end{array}$ & $\begin{array}{l}443(20.2) \\
1246(26.1)\end{array}$ & $\begin{array}{l}1,600(73.1) \\
3,110(65.2)\end{array}$ & 44.187 & $<0.001$ \\
\hline \multicolumn{6}{|c|}{ No. of children in the family } \\
\hline $\begin{array}{l}1-2 \\
\text { Above } 2\end{array}$ & $\begin{array}{l}338(7.1) \\
228(10.5) \\
\end{array}$ & $\begin{array}{l}1112(23.2) \\
577(26.5) \\
\end{array}$ & $\begin{array}{l}3,341(69.7) \\
1,369(63.0)\end{array}$ & 38.641 & $<0.001$ \\
\hline \multicolumn{6}{|l|}{ Mother's BMI } \\
\hline $\begin{array}{l}\text { Thin } \\
\text { Normal } \\
\text { Overweight }\end{array}$ & $\begin{array}{l}222(14.2) \\
291(7.2) \\
50(3.7)\end{array}$ & $\begin{array}{l}506(32.2) \\
961(23.9) \\
210(15.6)\end{array}$ & $\begin{array}{l}841(53.6) \\
2,774(68.9) \\
1,085(80.7)\end{array}$ & 269.996 & $<0.001$ \\
\hline
\end{tabular}

\begin{tabular}{|c|c|c|c|c|}
\hline \multirow[t]{2}{*}{ Covariates } & \multicolumn{2}{|l|}{ Model I } & \multicolumn{2}{|l|}{ Model II } \\
\hline & Reg. Coef. & OR $(95 \%) \mathrm{Cl}$ & Reg. Coef. & OR $(95 \%) \mathrm{Cl}$ \\
\hline $\begin{array}{l}\text { Intercept }\left(\alpha_{1}\right) \\
\text { Intercept }\left(\alpha_{2}\right)\end{array}$ & $\begin{array}{l}-2.823 \\
-1.210 \\
\end{array}$ & $\begin{array}{l}- \\
- \\
\end{array}$ & $\begin{array}{l}-2.067 \\
-0.426 \\
\end{array}$ & $\begin{array}{l}- \\
- \\
\end{array}$ \\
\hline \multicolumn{5}{|l|}{ ANC visit } \\
\hline $\begin{array}{l}\text { No (Ref.) } \\
\text { Yes }\end{array}$ & $\begin{array}{l}- \\
-0.592 \\
\end{array}$ & - $0.552(0.463,0.659)^{* * *}$ & $\begin{array}{l}- \\
-0.204 \\
\end{array}$ & $\begin{array}{l}- \\
0.815(0.665,0.972)^{*}\end{array}$ \\
\hline \multicolumn{5}{|l|}{ ANC provider } \\
\hline $\begin{array}{l}\text { Unskilled (Ref.) } \\
\text { Skilled }\end{array}$ & $\begin{array}{l}- \\
-0.321\end{array}$ & $\begin{array}{l}- \\
0.725(0.622,0.844)^{* * *}\end{array}$ & $-\overline{0}$ & $\begin{array}{l}- \\
1.025(0.880,1.225)\end{array}$ \\
\hline \multicolumn{5}{|l|}{ Child's age (months) } \\
\hline $\begin{array}{l}0-11 \text { (Ref.) } \\
12-23 \\
\text { Above } 24 \\
\end{array}$ & & & $\begin{array}{l}- \\
0.728 \\
1.015 \\
\end{array}$ & $\begin{array}{l}- \\
2.071(1.560,2.538)^{* * *} \\
2.759(2.253,3.362)^{* * *}\end{array}$ \\
\hline \multicolumn{5}{|l|}{ Father's education } \\
\hline $\begin{array}{l}\text { Primary or below (Ref.) } \\
\text { Secondary or higher }\end{array}$ & & & $\begin{array}{l}- \\
-0.225 \\
\end{array}$ & $\begin{array}{l}- \\
0.798(0.656,0.934)^{* *}\end{array}$ \\
\hline \multicolumn{5}{|l|}{ Mother's education } \\
\hline $\begin{array}{l}\text { Primary or below (Ref.) } \\
\text { Secondary or higher }\end{array}$ & & & $\begin{array}{l}- \\
-0.282 \\
\end{array}$ & $\begin{array}{l}- \\
0.754(0.614,0.887)^{* *}\end{array}$ \\
\hline \multicolumn{5}{|l|}{ Wealth index } \\
\hline $\begin{array}{l}\text { Poor (Ref.) } \\
\text { Middle } \\
\text { Wealthy }\end{array}$ & & & $\begin{array}{l}- \\
-0.326 \\
-0.576 \\
\end{array}$ & $\begin{array}{l}- \\
0.722(0.621,0.869)^{* * *} \\
0.562(0.453,0.716)^{* * *}\end{array}$ \\
\hline \multicolumn{5}{|l|}{ Place of residence } \\
\hline $\begin{array}{l}\text { Urban (Ref.) } \\
\text { Rural }\end{array}$ & & & - & $\begin{array}{l}- \\
1.265(0.948,1.626)\end{array}$ \\
\hline \multicolumn{5}{|c|}{ No. of children in the family } \\
\hline $\begin{array}{l}1-2 \text { (Ref.) } \\
\text { Above } 2\end{array}$ & & & - & $\begin{array}{l}- \\
1.077(0.911,1.271)\end{array}$ \\
\hline
\end{tabular}




\begin{tabular}{|c|c|c|c|c|}
\hline \multirow[t]{2}{*}{ Covariates } & \multicolumn{2}{|l|}{ Model I } & \multicolumn{2}{|l|}{ Model II } \\
\hline & Reg. Coef. & OR $(95 \%) \mathrm{Cl}$ & Reg. Coef. & OR $(95 \%) \mathrm{Cl}$ \\
\hline \multicolumn{5}{|c|}{ Mother's BMI } \\
\hline Thin (Ref.) & & & - & - \\
\hline Normal & & & -0.556 & $0.573(0.468,0.698)^{* * *}$ \\
\hline Overweight & & & -0.935 & $0.393(0.275,0.483)^{* * *}$ \\
\hline
\end{tabular}

*** $p$-value $<0.001, * * p$-value $<0.01, * p$-value $<0.05 ;$ Ref. - reference category.

it can be seen that the proportion of severely and moderately malnourished children were found to be higher among children above 24 months of age (9.1\% and $27.9 \%)$, having a father with primary or lower education ( $11.3 \%$ and $29.4 \%)$, having a mother with primary or lower education (11.1\% and $28.4 \%)$ and receiving no antenatal care visit $(13.0 \%$ and $27.5 \%)$ during pregnancy, coming from a poor income family $(13.1 \%$ and $30.1 \%)$, having a thin mother (14.2\% and $32.2 \%)$, living in a rural area $(8.8 \%$ and $26.1 \%)$ and a family having more than two children (10.5\% and $26.5 \%)$. This rate was also higher among children having a mother who received ANC service from an unskilled ANC provider ( $8.8 \%$ and $22.1 \%$ ). All the selected covariates were found significant considering the nutrition status of children $(p<0.001)$.

\section{Regression analysis}

The main objective of this study was to assess the link between ANC services and child malnutrition in Bangladesh. For this purpose, we considered two cumulative logit regression models. The parameter estimates of these two models are shown in Table 2. In Model I, only two covariates (ANC visit and ANC provider) were considered to measure the unadjusted effects of ANC service. It can be observed that both the variables had a significant $(p<0.01)$ effect on the nutritional status of children. For example, the odds of staying in the worse state of nutritional status (severely and moderately malnourished) is $[(1-0.552) \times 100]=45 \%$ lower for children with a mother who received ANC service compared to a mother who received no ANC service. These odds are $25 \%$ lower for a mother who received ANC service from skilled ANC providers. Besides these two covariates, we incorporated several demographic and clinical covariates into Model II (Table 2). From this model, it can be observed that the effect of an ANC visit on child malnutrition is still significant $(p<0.05)$. This implies that an ANC visit during pregnancy is an important factor for child malnutrition in Bangladesh, as it is found statistically significant even after controlling the demographic and clinical variables. However, it is surprising to see that in Model II, the nature of the ANC provider had no significant effect on the nutrition status of children.

It is also evident from Model II that the odds of remaining within the severely and moderately malnourished category of a child's nutrition status is more than double for children belonging to the age group $12-23$ months $(O R=2.071, p<0.001)$ and above 24 months $(O R=2.759, p<0.001)$, when compared to infants. These odds are significantly lower for fathers with secondary or higher education (OR $=0.798, p<0.01)$, mothers with secondary or higher education $(O R=0.754, p<0.01)$, coming from a middle $(\mathrm{OR}=0.722, p<0.001)$ and wealthy $(\mathrm{OR}=$ $0.562, p<0.001)$ income family, having a normal $(\mathrm{OR}=0.573$, $p<0.001)$ or overweight $(\mathrm{OR}=0.393, p<0.001)$ mother. However, residential status $(O R=1.265, p<0.05)$ and number of children in the family $(O R=1.077, p>0.05)$ were found to have no significant effect on child malnutrition in this study.

\section{Discussion}

This study aimed at examining the relationship between antenatal care services and the nutritional status of children in order to determine the risk factors of child malnutrition in Bangladesh. We found through our analyses that child malnutrition had a potential association with the child's age, mother's and father's education, antenatal care visits, wealth index and mother's BMI, which is consistent with existing literature $[2,22$, 23]. We observed that antenatal care visits had a significant effect on child malnutrition, as mothers who received antenatal care visits gave birth to more nourished children compared to mothers who did not receive any kind of antenatal care service. This finding corresponds with previous works as well [24, 25]. We also found that a mother's body mass index is linked with the nourishment of children, which complies with similar types of studies $[10,11]$.

Although a child's nutritional status is associated with antenatal care visits, whether a patient will receive maternal care or antenatal care depends largely on different factors, such as the family's financial status, head of the family, partner's educational status, the relationship that the mother shares with other family members and the presence of a skilled birth attendant during the delivery period [26-29]. Socio-demographic factors, such as educational status of mothers and household income, play a vital role in determining the nutritional status of children as well $[30,31]$. Our findings also imply that mothers who were more educated and were comparably wealthier gave birth to nourished children.

The provision of antenatal care (ANC) has been expanding fast worldwide. It offers a range of diversified services which can prevent, detect and treat risk factors early in pregnancy. ANC is often used as a platform for additional interventions, showing a positive influence on maternal and child health status, such as nutrition programs and breastfeeding counselling, or to educate women about the possibilities of family planning and birth spacing [32-34]. In addition, ANC programs are used to provide care and information that is not directly related to pregnancy, but which can reduce possible maternal risk factors, such as promoting healthy lifestyles, tackling malnutrition or informing about gender-based violence. Hence, the knowledge of ANC has become one of the most fundamental parts of basic primary healthcare professionals. By addressing the importance of primary health care, the government of Bangladesh has taken initiatives to revitalize community clinics. One of such projects, entitled 'Revitalization of Community Health Care Initiatives in Bangladesh', is aimed at providing services including antenatal care, integrated management of childhood illness, reproductive health and family-planning, nutrition education, etc., where healthcare professionals can contribute to a greater extent.

Both existing literature and the findings from the present study suggest that antenatal care services can reduce child malnutrition to a great extent. Besides this, providing women with proper knowledge and counseling during pregnancy might improve the child's health and reduce delivery complexities. In particular, emergencies during pregnancy, regular check-ups and skilled delivery assistance should be emphasized. Public education and awareness programs should be increased to prevent women from seeking dangerous ANC alternatives. Though ANC services are mostly available both in rural and urban areas and do not differ much in terms of the child's nutritional status, these services should be made more affordable for the impov- 
erished. Alongside this, further research on ANC visits and child nutrition need to be conducted in the future for a greater understanding of the potential link-ups between malnutrition and other issues.

\section{Limitations of this study}

This study is based on data extracted from the Bangladesh Demographic and Health Survey (BDHS) 2014, which exerts certain limitations. We acknowledge that the study would have even more value if we could obtain more information regarding the effect of antenatal visits on the number of breastfed children and the duration of breastfeeding. Unfortunately, this information was not available in the BDHS dataset. We also did not have disaggregated information on the type of provider (skilled/unskilled) for each ANC visit. We attempted to proxy this by considering the women who receive ANC service at least once from a skilled provider during her pregnancy.

\section{Conclusions}

This study provides evidences of a significant link between ANC visits and child malnutrition in Bangladesh. The study ex- plores important association between the child's age, parent's education, wealth index, mother's BMI and child nutrition. The findings are crucial to the formulation of strategies and interventions for reducing the prevalence of child malnutrition in Bangladesh. More investment in the health sector and interventions aimed at improving antenatal care services and a child's health is recommended to decrease child malnutrition and maternal deaths. Improved education and income opportunity, along with empowerment of women, are vital for long-term results. The primary healthcare professional can play a greater role here and should be facilitated more in antenatal care services for better results. Antenatal care service should also be made more available and affordable for the population.

Acknowledgements. We would like to thank the National Institute of Population Research and Training NIPORT, Bangladesh, and MEASURE DHS for allowing us to use BDHS 2014 data for our analysis. We also thank the reviewers and editor for their valuable comments and suggestions that helped us to improve the previous version of this paper.

Source of funding: This work was funded by the authors' own resources.

Conflicts of interest: The authors declare no conflicts of interest.

\section{References}

1. Chang SY, Ge KY. Definition and measurement of child malnutrition. Biomed Environ Sci 2011; 14(4): $283-291$.

2. Rahman M. Association between order of birth and chronic malnutrition of children: a study of nationally representative Bangladeshi sample. Cad Saude Publica 2016; 32(2): e00011215, doi: 10.1590/0102-311X00011215.

3. de Onis M, Frongillo EA, Blössner M. Is malnutrition declining? An analysis of changes in levels of child malnutrition since 1980. Bull World Health Organ 2000; 78(10): 1222-1233.

4. Lartey A. What would it take to prevent stunted growth in children in sub-Saharan Africa? Proc Nutr Soc 2015; 74(4): 449-453, doi: $10.1017 /$ S0029665115001688.

5. Seb Rengma M, Bose K, Mondal N. Socio-economic and demographic correlates of stunting among adolescents of Assam, North-east India. Anthropol Rev 2016; 79(4): 409-425.

6. Kavosi E, Rostami ZH, Kavosi Z, et al. Prevalence and determinants of under-nutrition among children under six: a cross-sectional survey in Fars province, Iran. Int J Health Policy Manag 2014; 3(2): 71-76.

7. Fenske N, Burns J, Hothorn T, et al. Understanding child stunting in India: a comprehensive analysis of socio-economic, nutritional and environmental determinants using additive quantile regression. PLOS ONE 2013; 8(11): e78692, doi: 10.1371/journal.pone.0078692.

8. McSweeney L, Rapley T, Adamson A. The preschool child, food photography and a parent's bed: a feasibility study to determine acceptable visual data collection methods. J Nutr Health Sci 2015; 2(4): 406, doi: 10.15744/2393-9060.2.406.

9. Titaley CR, Dibley MJ, Roberts CL. Factors associated with underutilization of antenatal care services in Indonesia: results of Indonesia Demographic and Health Survey 2002/2003 and 2007. BMC Public Health 2010; 10: 485, doi: 10.1186/1471-2458-10-485.

10. Negash C, Whiting S, Henry C, et al. Association between maternal and child nutritional status in Hula, Rural Southern Ethiopia: a cross sectional study. PLOS ONE 2015; 10(11): e0142301, doi: https://doi.org/10.1371/journal.pone.0142301.

11. Felisbino-Mendes MS, Villamor E, Velasquez-Melendez G. Association of maternal and child nutritional status in Brazil: a population based cross-sectional study. PLOS ONE 2014; 9(1): e87486, doi: 10.1371/journal.pone.0087486.

12. Bhattacharya S, Campbell DM, Liston WA, et al. Effect of Body Mass Index on pregnancy outcomes in nulliparous women delivering singleton babies. BMC Public Health 2007; 7: 168.

13. Das S, Hossain MZ. Levels and determinants 2016 of child malnutrition in Bangladesh. Pak J Statist 2008; 24(4): 301-323.

14. Rayhan MI, Khan MSH. Factors causing malnutrition among under five children in Bangladesh. Pak J Nutr 2006; 5(6): 558-562.

15. Harpham T, Huttly S, De Silva MJ, et al. Maternal mental health and child nutritional status in four developing countries. J Epidemiol Community Health 2005; 59(12): 1060-1064.

16. Fotso JC. Child health inequities in developing countries: differences across urban and rural areas. Int J Equity Health 2006; 5: 9, doi: 10.1186/1475-9276-5-9.

17. Houweling TA, Ronsmans $C$, Campbell OM, et al. Huge poor-rich inequalities in maternity care: an international comparative study of maternity and child care in developing countries. Bull World Health Organ 2007; 85(10): 745-754.

18. Abdulla MM. Assessment and determinants of nutritional status in a sample of under five-year-old Iraqi children. Eur J Biol Med Sci Res 2016; 4(4): 1-24.

19. Asfaw $\mathrm{M}$, Wondaferash $\mathrm{M}$, Taha $\mathrm{M}$, et al. Prevalence of under nutrition and associated factors among children aged between six to fifty nine months in Bule Hora district, South Ethiopia. BMC Public Health 2015; 15: 41, doi: 10.1186/s12889-015-1370-9.

20. National Institute of Population Research and Training (NIPORT), Mitra and Associates, Macro International, 2016. Bangladesh Demographic and Health Survey 2014. Dhaka and Calverton, Maryland, US: NIPORT, Mitra and Associates, and Macro International. Available from URL: https://dhsprogram.com/publications/publication-fr311-dhs-final-reports.cfm.

21. World Health Organization. Anthro for Personal Computers, Version 3.2.2, 2011: Software for Assessing Growth and Development of the World's Children. Geneva: WHO; 2011 [cited 30.06.2017]. Available from URL: http://www.who.int/childgrowth/software/en/.

22. Srivastava A, Mahmood SE, Srivastaval PM, et al. Nutritional status of school-age children - a scenario of urban slums in India. Arch Public Health 2012; 70(1): 8, doi: 10.1186/0778-7367-70-8.

23. Zewdie T, Abebaw D. Determinants of child malnutrition: empirical evidence from Kombolcha District of Eastern Hararghe Zone, Ethiopia. Quar J Int Agri 2013; 52(524): 357-372. 
24. Hamel C, Enne J, Omer K, et al. Childhood malnutrition is associated with maternal care during pregnancy and childbirth: a Cross-Sectional Study in Bauchi and Cross River States, Nigeria. J Public Health Res 2015; 4(1): 408, doi: http://doi.org/10.4081/jphr.2015.408.

25. Endris N, Asefa H, Dube L. Prevalence of malnutrition and associated factors among children in Rural Ethiopia. BioMed Res Int 2017; 2017, doi:10.1155/2017/6587853.

26. Fuchs $\mathrm{C}$, Sultana $\mathrm{T}$, Ahmed T, et al. Factors associated with acute malnutrition among children admitted to a Diarrhoea Treatment Facility in Bangladesh. Int J Pediatr 2014; 2014, doi: http://dx.doi.org/10.1155/2014/267806.

27. Mumtaz Z, Salway SM. Gender, pregnancy and the uptake of antenatal care services in Pakistan. Sociol Health IIIn 2007; 29(1): 1-26.

28. Saya L, Raine R. A systematic review of inequalities in the use of maternal health care in developing countries: examining the scale of the problem and the importance of context. Bull World Health Organ 2007; 85(10): 812-819.

29. Sarki M, Robertson A, Parlesak A. Association between socioeconomic status of mothers, food security, food safety practices and the double burden of malnutrition in the Lalitpur district, Nepal. Arch Public Health 2016; 74(1): 35, doi: 10.1186/s13690-016-0150.

30. Abuya BA, Ciera J, Kimani-Murage E. Effect of mother's education on child's nutritional status in the slums of Nairobi. BMC Pediatrics 2012; 12: 80, doi: http://doi.org/10.1186/1471-2431-12-80.

31. Ali Naser I, Jalil R, Wan Muda WM, et al. Association between household food insecurity and nutritional outcomes among children in Northeastern of Peninsular Malaysia. Nutr Res Pract 2014; 8(3): 304-311, doi: http://doi.org/10.4162/nrp.2014.8.3.304.

32. Black RE, Victora CG, Walker SP, et al. Maternal and child undernutrition and overweight in low-income and middle-income countries. Lancet 2013; 382: 427-451.

33. Imdad A, Bhutta ZA. Effects of calcium supplementation during pregnancy on maternal, fetal and birth outcomes. Paediatr Perinat Epidemiol 2012; 26(Suppl. 1): 138-152.

34. McNellan CR, Dansereau E, Colombara D, et al. Uptake of antenatal care, and its relationship with participation in health services and behaviors: an analysis of the poorest regions of four Mesoamerican countries. Ann Glob Health 2017; 83: 193-204.

Tables: 2

Figures: 0

References: 34

Received: 04.05.2018

Reviewed: 15.05 .2018

Accepted: 14.06.2018

Address for correspondence:

Ashis Talukder, MSc

Khulna University

Khulna-9208

Bangladesh

Tel.: +8801772063507

E-mail: ashistalukder27@yahoo.com 